\title{
Prevalence of Congenital Anomalies in Polyhydramnios: A Hospital based study from Western Nepal
}

\author{
Lalchan $\mathrm{S}^{1}$, Sharma $\mathbf{P}^{1}$, Gurung SD ${ }^{2}$ \\ ${ }^{1}$ Department of Radiology and Imaging, Manipal Teaching Hospital, Pokhara \\ ${ }^{2}$ Department of Obstetric and Gynaecology, Manipal Teaching Hospital, Pokhara
}

Received: December 10, 2017

Accepted: February 1, 2018

Published: June 30, 2018

Cite this paper:

Lalchan S, Sharma P, Gurung SD. Prevalence of Congenital Anomalies in Polyhydramnios: A Hospital based study from western Nepal. Nepalese Journal of Radiology 2018;8(11):25-29.http://dx.doi.org/10.3126/njr.v8i1.20452

\begin{abstract}
Introduction: Polyhydramnios is excessive amount of amniotic fluid in relation to gestational age. It is frequently associated with congenital anomalies of the fetus. The aim of this study was to see the prevalence of congenital anomalies in polyhydramnios.

Methods: Singleton pregnant irrespective of gestational age with amniotic fluid index more than 25 were included in the study. Degree of polyhydramnios was graded as mild, moderate and severe. Detail study of fetus was done for possible congenital anomalies. Congenital anomalies were confirmed with post-natal findings.

Results: There were 39 pregnant women with amniotic fluid index (AFI) $>25 \mathrm{~cm}$. Prevalence of polyhydramnios was $0.3 \%$. Congenital anomalies were present in $31.6 \%$ of pregnant women with polyhydramnios. In pregnant women with severe polyhydramnios; $66.6 \%$ had congenital anomalies. Central nervous system, gastrointestinal and skeletal anomalies were the frequent anomalies associated with polyhydramnios.
\end{abstract}

Conclusion: Polyhydramnios is associated with increased risk of congenital anomalies hence a detail survey of fetus should be done for possible congenital anomalies.

Key Words: Congenital Malformation; Prevalance; Polyhydramnios

\section{INTRODUCTION}

The amniotic fluid is required for the proper growth and development of the fetus. The fetus is prevented from trauma by its cushion effect. It also acts as a barrier against infection and helps in fetal lung maturity. It varies with gestational age. Fetal urine;

Correspondence to: Dr. Subita Lalchan Department of Radiology

Manipal Teaching Hospital, Pokhara, Nepal Email: subita_lalchan@hotmail.com secretion from fetal lung, oral and nasal cavities; movement of water and metabolites

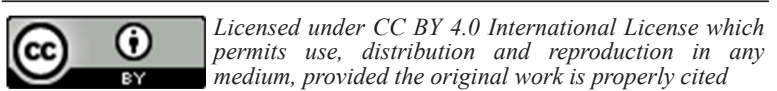


between the placenta and the fetal blood and transudation of water and electrolytes across the amnion and chorion; movement of water across fetal skin and fetal swallowing are the sources influencing amniotic fluid volume. ${ }^{1}$ Polyhydramnios is the excess of the amniotic fluid relative to the gestational age. It occurs in $1 \%$ of pregnancies. ${ }^{2}$ It may be associated with adverse fetal and maternal outcome. The aim of this study was to find the association between polyhydramnios and congenital malformations in pregnant women of western Nepal. To the best of our knowledge, no such study has been done in our part.

\section{METHODS}

This prospective study was conducted in the department of Radiology between January 2014 and June 2016. All the singleton pregnant ladies irrespective of gestational age with amniotic fluid index more than 25 were included in the study. Ultrasonography was done in supine position in GE Logiq P3 machine. Ultrasound transducer was held along the maternal longitudinal axis and was held perpendicular to the floor during measurement of amniotic fluid index. External pressure over maternal abdomen with transducer was avoided. Uterus was divided into four imaginary quadrants. Measurement was done in the pocket free of fetal limbs and umbilical cord. Amniotic fluid index was calculated by summation of deepest pocket in each quadrant. The degree of polyhydramnios was categorized as mild (AFI: $25.1-30 \mathrm{~cm}$ ), moderate (AFI: 30.1-35 $\mathrm{cm})$ and severe $(\mathrm{AFI}>35 \mathrm{~cm}){ }^{3,4,5}$ Ladies with chronic illness, cardiac disease and multifetal pregnancy were excluded.

Detailed anomaly scan was done to look for congenital malformations. All the pregnant ladies were followed till delivery. Detailed physical examinations of new born babies were done and evaluated for congenital malformation.
Prior approval from the institutional review was done before the study.

Statistical analysis was done using SPSS (version16).

\section{RESULTS}

There were 39 pregnant ladies with amniotic fluid index (AFI) of $>25 \mathrm{~cm}$ during the study period. One of the pregnant lady with history of cardiac disease was excluded from the study. A total of 38 pregnant ladies with polyhydramnios were included for statistical analysis. Total deliveries during that period were 10,342. So the prevalence of polyhydramnios was $0.3 \%$.

Mean age of the pregnant ladies was $28.8 \pm 6.3$ years. Most of the ladies were in the age group of 26-30 years (Table 1).

Table 1: Age distribution of pregnant ladies

\begin{tabular}{|l|l|l|} 
Age Group & Frequency & Percentage \\
\hline $20-25$ & 12 & 31.6 \\
\hline $26-30$ & 13 & 34.2 \\
\hline $31-35$ & 6 & 15.8 \\
\hline $36-40$ & 7 & 18.4 \\
\hline Total & 38 & 100 \\
\hline
\end{tabular}

Half of the ladies were more than 37 weeks of gestation at the time of examination (Table 2).

\section{Table 2: Distribution of pregnant ladies according to gestational age}

\begin{tabular}{|l|l|l|}
\hline $\begin{array}{l}\text { Gestational Age } \\
<20 \text { weeks }\end{array}$ & 1 & 2.6 \\
\hline $\begin{array}{l}\text { 20 Weeks to } 34 \\
\text { Weeks }\end{array}$ & 13 & 34.2 \\
\hline $\begin{array}{l}34 \text { weeks 1 day to } \\
37 \text { weeks }\end{array}$ & 5 & 13.2 \\
\hline$>37$ weeks & 19 & 50 \\
\hline Total & 38 & 100 \\
\hline
\end{tabular}


Polyhydramnios was categorized as mild (AFI: 25.1-30 cm), moderate (AFI: 30.1$35 \mathrm{~cm}$ ) and severe (AFI $>35 \mathrm{~cm}$ ). Out of 38 pregnant ladies, $71.1 \%$ had mild polyhydramnios (Table 3 ).

\section{Table 3: Severity of Polyhydramnios}

\begin{tabular}{|l|l|l|}
\hline $\begin{array}{l}\text { Polyhydram- } \\
\text { nios }\end{array}$ & Frequency & Percentage \\
\hline $\begin{array}{l}\text { Mild (AFI: } \\
25.1-30 \mathrm{~cm})\end{array}$ & 27 & 71.1 \\
\hline $\begin{array}{l}\text { M o d e r t e } \\
\text { AFI: 30.1- } \\
35 \mathrm{~cm})\end{array}$ & 5 & 3.2 \\
\hline $\begin{array}{l}\text { Severe (AFI } \\
>35 \mathrm{~cm})\end{array}$ & 6 & 15.8 \\
\hline Total & 38 & 100 \\
\hline
\end{tabular}

Congenital anomalies were present in 31.6 $\%$ of pregnant ladies with polyhydramnios (Figure 1).

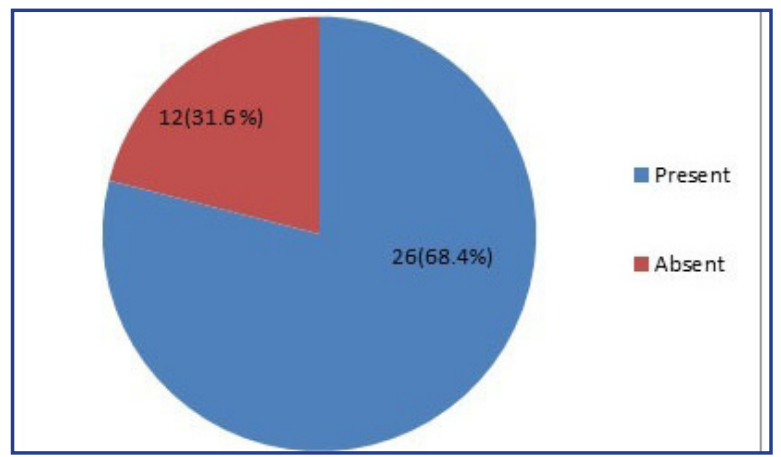

Figure 1: Diagram showing distribution of congenital anomalies

Among the various congenital malformations diagnosed by ultrasonography; central nervous system (CNS), Gastrointestinal (GI) and Skeletal malformations were the commonest (Table 4).

Congenital anomalies increased with severity of polyhydramnios (Table 5).

\section{Table 4: Type of Congenital Anomalies}

\begin{tabular}{|l|l|l|}
\hline Type of Anomalies & Frequency & $\begin{array}{l}\text { Meningomyelocele-1, Hydrocephalus -1, Holopros- } \\
\text { encephaly -1 }\end{array}$ \\
\hline Central Nervous System & 3 & $\begin{array}{l}\text { Club foot -1, Spinal kyphoscoliosis-1 and Rocker } \\
\text { Bottom foot (Edwards Syndrome) -1 }\end{array}$ \\
\hline Gastrointestinal & 3 & Oesophageal atresia -2, Duodenal atresia-1 \\
\hline Mandibular Hypoplasia & 1 & Pierre Robin syndrome \\
\hline Hydrops Foetalis & 1 & \\
\hline Facial Anomalies & 1 & Cleft lip \\
\hline Total & 12 & \\
\hline
\end{tabular}

Table 5: Correlation of congenital anomalies with severity of polyhydramnios

\begin{tabular}{|l|l|l|l|}
\hline Severity of Polyhydramnios & Congenital anomalies & Total \\
\hline & Absent & Present & \\
\hline Mild $(25.1-30 \mathrm{~cm})$ & 21 & 6 & 27 \\
\hline Moderate $(30.1-35 \mathrm{~cm})$ & 3 & 2 & 5 \\
\hline Severe $(>35 \mathrm{~cm})$ & 2 & 4 & 6 \\
\hline Total & 26 & 12 & 38 \\
\hline
\end{tabular}




\section{DISCUSSION}

This prospective study was done during the period of two and half years. A total of 38 pregnant ladies with diagnosis of polyhydramnios were included in the study. Prevalence of polyhydramnios was $0.3 \%$ which is similar to the studies by Thompson $\mathrm{O}$ et $\mathrm{al}^{6}$ and Kirkinen et al. ${ }^{7}$ Bundgaard A et al have reported a higher prevalence of the disease. $^{8}$

Most of our pregnant ladies were in the age group 26-30 years. Half of our patients with polyhydramnios presented after 37 weeks of gestation. Most of our patients had mild polyhydramnios. A lower frequency of occurrence of congenital malformations was seen in this group, which is consistent with the data published by other authors..$^{9,10,11}$

The most common form of polyhydramnios in our study was an idiopathic one, found in approximately $68 \%$ of patients. It is consistent with the observation of other authors., ${ }^{9}, 12,13$

There is an association of polyhydramnios with congenital malformation. ${ }^{9}$ Six out of 27 patients with mild polyhydramnios $(22 \%)$ had congenital malformations. Similarly, out of five patients with moderate polyhydramnios, congenital malformation was seen in 2 $(40 \%)$ patients. Severe polyhydramnios was seen in 6 patients, out of which 4 $(66.6 \%)$ had congenital malformations. There is also increased association between severity of polyhydramnios and congenital malformations in studies by other authors. ${ }^{9}$ In a study by Pri-Paz et al; high incidence of anomalies (79.1\%) was seen in fetuses of mother with severe polyhydramnios $(\geq 35$ $\mathrm{cm}) .{ }^{14}$

There were no cardiac anomalies in the present study. In contrast to this, cardiac anomalies were most frequently associated with polyhydramnios as described by Pri-Paz et al
${ }^{14}$ and Boito et al ${ }^{15}$. Central nervous system, Gastrointestinal and skeletal anomalies are among the highest in the present study. In a study by Kornacki et $\mathrm{al}^{9}$ gastrointestinal tract anomalies were the most frequent congenital anomalies in polyhydramnios, especially in severe polyhydramnios.

\section{CONCLUSION}

Congenital anomalies are associated with polyhydramnios. The prevalence of congenital anomalies is more with severe polyhydramnios. Hence detail anomaly scan is necessary in cases of poyhydramnios.

\section{CONFLICT OF INTEREST}

None

\section{SOURCES OF FUNDING}

None

\section{REFERENCES}

1 Modena

$\mathrm{AB}$,

Fienin

S.

Amniotic fluid dynamics. Acta Biomed 2004;75(suppl):11-13.

Available from: https://www.ncbi.nlm. nih.gov/pubmed/15301282[Accessed 6th November 2017].

2 YefetE, Daniel- Spiegel E.Outcomes from polyhydramnios with normal ultrasound. Pediatrics $2016 ; 137$ ( 2) ) e 20151948 . https://doi.org/10.1542/peds.2015-1948

3 Many A, Hill LM, Lazebnik N, Martin JG. The association between polyhydramnios and preterm delivery. Obstet Gynecol 1995;86:389-391. https://doi.org/10.1016/00297844(95)00179-U

4 HamzaA, Herr D, SolomayerEF, MeybergSolomayer G. Polyhydramnios: Causes, Diagnosis and Therapy. Geburtshilfe Frauenheilkd 2013;73(12):1241-1246. 
https://doi.org/10.1055/s-0033-1360163

5 Phelen JP, Martin GI. Polyhydramnios: fetal and neonatal implications. Clin Perinatal 1989;16:987-994. https://doi.org/10.1016/S0095$\underline{\text { 5108(18)30616-X }}$

6 Thompson O, Brown R, Gunnarson G, Harrington K. Prevalence of polyhydramnios in the third trimester in a population screened by first and second trimester ultrasonography. $J \quad$ Perinat Med1998;26(5):371-377. ht tps://doi.org/10.1515/ jpme.1998.26.5.371

7 Kirkinen P, Jouppila P: Polyhydramnios. A clinical study. Ann Chir Gynaecol 1978;67 (3):117-122. Available from: https://www.ncbi.nlm. nih.gov/pubmed/356706[Accessed 10th November 2017].

8. Bundgaard A, Andersen BR, Rode L, Lebech M, Tabor A. Prevalence of polyhydramnios at a Danish hospital- a population based study. Acta Obstet Gynecol Scand $2007 ; 86: 1427-1431$.

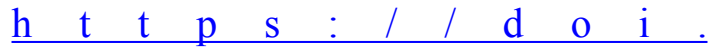
org/10.1080/00016340701447569

9. Kornacki J, Adamczyk M, Wirstlein $\mathrm{P}$, Osiński M, Wender-Ożegowska E. Polyhydramnios - frequency of congenital anomalies in relation to the value of the amniotic fluid index. Ginekol Pol 2017;88(8):442-445. https://doi.org/10.5603/GP.a2017.0081

10. Harman CR. Amniotic fluid abnormalities. Semin Perinatol 2008;32(4):288-294. https://doi.org/10.1053/j. semperi.2008.04.012

11. Dashe JS, McIntire DD, Ramus RM, Santos-Ramos R, Twickler DM. Hydramnios: anomaly prevalence and sonographic detection. Obstet Gynecol 2002;100(1):134-139. https://doi.org/10.1097/00006250-

\section{$\underline{200207000-00021}$}

12. Pasquini L, Seravalli V, Sisti G et al. Prevalence of a positive TORCH and parvovirus B19 screening in pregnancies complicated by polyhydramnios. Prenat Diagn 2016; 36(3):290-293. https://doi.org/10.1002/pd.4769

13. Magann EF, Chauhan SP, Doherty DA, Lutgendorf MA, Magann MI, Morrison JC. A review of idiopathic hydramnios and pregnancy outcomes. Obstet Gynecol Surv 2007; 62(12):795-802. https://doi.org/10.1097/01. ogx.0000290349.58707.e0

14. Pri-Paz S, Khalek N, Fuchs KM, Simpson LL. Maximal amniotic fluid index as a prognostic factor in pregnancies complicated by polyhydramnios. Ultrasound Obstet Gynecol 2012;39(6):648-653. https://doi.org/10.1002/uog.10093

15. Boito S, Crovetto F, Ischia $B$ et al. Prenatal ultrasound factors and genetic disorders in pregnancies complicated by polyhydramnios. Prenat Diagn 2016;36(8):726-730. https://doi.org/10.1002/pd.4851 